\title{
Caenorhabditis elegans LET-767 is able to metabolize androgens and estrogens and likely shares common ancestor with human types 3 and $1217 \beta$-hydroxysteroid dehydrogenases
}

\author{
Serge Desnoyers ${ }^{1}$, Pierre-Gilles Blanchard ${ }^{2}$, Jean-François St-Laurent ${ }^{1}$, Steve N Gagnon ${ }^{1}$, David L Baillie ${ }^{3}$ \\ and Van Luu-The ${ }^{2}$ \\ ${ }^{1}$ Pediatrics Research Unit and ${ }^{2}$ Oncology and Molecular Endocrinology Research Center, Laval University Medical Center (CHUL) and Laval University, 2705 \\ Laurier Boulevard, Quebec, G1V 4G2 Canada \\ ${ }^{3}$ Department of Molecular Biology and Biochemistry, Simon Fraser University, Burnaby, V5A 1S6 Canada \\ (Correspondence should be addressed to S Desnoyers; Email: serge.desnoyers@crchul.ulaval.ca)
}

\begin{abstract}
Mutations that inactivate LET-767 are shown to affect growth, reproduction, and development in Caenorhabditis elegans. Sequence analysis indicates that LET-767 shares the highest homology with human types 3 and $1217 \beta$-hydroxysteroid dehydrogenases (17 $\beta-H S D 3$ and 12). Using LET-767 transiently transfected into human embryonic kidney-293 cells, we have found that the enzyme catalyzes the transformation of both 4-androstenedione into testosterone and estrone into estradiol, similar to that of mouse $17 \beta-H S D 12$ but different from human and primate enzymes that catalyze the transformation of estrone into estradiol. Previously, we have shown that amino acid F234 in human $17 \beta-H S D 12$ is responsible for the selectivity of the enzyme toward estrogens. To assess whether this amino acid position 234 in LET-767 could play a role in androgen-estrogen selectivity, we have changed the methionine M234 in LET-767
\end{abstract}

into $\mathrm{F}$. The results show that the M234F change causes the loss of the ability to transform androstenedione into testosterone, while conserving the ability to transform estrone into estradiol, thus confirming the role of amino acid position 234 in substrate selectivity. To further analyze the structure-function relationship of this enzyme, we have changed the three amino acids corresponding to lethal mutations in let-767 gene. The data show that these mutations strongly affect the ability of LET-767 to convert estrone into estradiol and abolish its ability to transform androstenedione into testosterone. The high conservation of the active site and amino acids responsible for enzymatic activity and substrate selectivity strongly suggests that LET-767 shares a common ancestor with human 17 $\beta-$ HSD3 and 12.

Journal of Endocrinology (2007) 195, 271-279

\section{Introduction}

The $17 \beta$-hydroxysteroid dehydrogenases (17 $\beta$-HSDs) are key enzymes responsible for the formation and the inactivation of sex steroids (Labrie et al. 1997, 2000, Luu-The 2001, Mindnich et al. 2004). Members of the $17 \beta-$ HSD family fall into two groups: the reductive and the oxidative $17 \beta$-HSDs. The reductive $17 \beta-H S D$ s produce active androgens and estrogens by catalyzing the formation of the hydroxy group at position $17 \beta$ of the steroid backbone. The oxidative 17 $\beta$-HSD transforms the hydroxy group into keto and inactivates the steroids. Type 3 $17 \beta-H S D(17 \beta-H S D 3)$ is a reductive $17 \beta-H S D$ present in the testis and catalyzes the transformation of 4 -androstenedione into testosterone (Geissler et al. 1994). Its deficiency is the cause of the male pseudohermaphroditism in affected boys. Human $17 \beta-H S D 12$ is structurally closely related to $17 \beta-H S D 3$. The similarities include conserved active site and cofactor binding site. Moreover, their genomic organization is similar: 11 exons of approximately the same size spanning large chromosomal regions, i.e., $240 \mathrm{~kb}$ for $17 \beta-\mathrm{HSD} 12$ and $103 \mathrm{~kb}$ for $17 \beta-H S D 3$. Therefore, $17 \beta-H S D 3$ and $17 \beta-H S D 12$ may be duplicate genes. Both genes have, however, evolved to acquire different substrate selectivity, androgen for $17 \beta-H S D 3$ and estrogen for 17 $\beta$-HSD12 in human and primates (Luu-The et al. 2006 , Liu et al. 2007). It is noteworthy that mouse $17 \beta-H S D 12$ catalyzes the transformation of both androgens and estrogens (Blanchard \& Luu-The 2007). In agreement with their role in the formation of active sex steroid and reproduction in human, $17 \beta-H S D 3$ is highly expressed in the testis, while $17 \beta-H S D 12$ is expressed significantly in the ovary and mammary gland (Luu-The et al. 2006).

The importance of steroid-metabolizing enzymes is not limited to mammals. Analysis of the Caenorhabditis elegans genome reveals the presence of up to six genes sharing high homology with 17ß-HSDs: let-767, dhs-5, stdh-1, stdh-2, tag-57, and C06B3.5 (WormBase web site, http://www.wormbase.org, release WS159, June 22, 2006). Of particular interest, Let-767 mutants show a reduction in growth and a decrease in brood size 
similar to the phenotype observed in wild-type worms grown in the absence of cholesterol (Merris et al. 2003). The data strongly suggest that LET-767 is involved in the metabolism of cholesterol (Kuervers et al. 2003). However, the enzymatic product that may be generated by LET-767 in C. elegans is most probably neither an androgen nor estrogen because it has been shown that androgen receptor (AR) and estrogen receptor (ER) are missing in C. elegans (Baker 2003, Bertrand et al. 2004).

Since LET-767 shows the highest homology with $17 \beta-$ HSD3 and 12, we would like to assess whether LET-767 is able to transform the substrates of these enzymes, namely androstenedione and estrone. In the present study, we show, using transformed human embryonic kidney (HEK-293) cells transiently expressing LET-767, that this enzyme catalyzes the conversion of estrone into estradiol, as well as 4-androstenedione into testosterone. Furthermore, sitedirected mutagenesis analysis correlates the inactivation of LET-767 enzymatic activity with the establishment of a lethal phenotype caused by developmental arrest. Taken together, our data strongly suggest that LET-767 shares a common ancestor with human 17ß-HSD3 and 12 genes.

\section{Materials and Methods}

\section{C. elegans strains}

The strained used in this study were obtained from the C. elegans Genetics Center (University of Minnesota, Minneapolis, MN, USA) and from the laboratory of Dr David Baillie (Simon Fraser University, British-Columbia, Canada). These include: the wild-type N2 var. Bristol strain, BC4849 sDp3 (III;f); dpy-17(estrone64) let-767(s2819) ncl-1(estrone865) unc-32(estrone89)III, BC4981 sDp3 (III;f); dpy-17(estrone64) let-767(s2176) unc-32(estrone89)III, BC4174 sDp3 (III;f); dpy-17(estrone64) let-767(s2464) unc-32(estrone89)III.

\section{Nematode culture and growth conditions}

C. elegans were handled and cultured according to standard protocol (Hope 1999) in order to prepare RNA and perform RNAi experiment. Briefly, worms were grown at $20^{\circ} \mathrm{C}$ on nematode growth medium (NGM) agar plates seeded with Escherichia coli strain OP50 as a source of food. For liquid cultures, worms were first grown on ten $9 \mathrm{~cm}$ plates until bacteria were cleared from the surface (usually 3 days). The worms were then transferred to $11 \mathrm{~S}$ basal medium $(0 \cdot 1 \mathrm{M}$ $\mathrm{NaCl}, 0.05 \mathrm{M} \mathrm{KH}_{2} \mathrm{PO}_{4} / \mathrm{K}_{2} \mathrm{HPO}_{4}, \mathrm{pH} 6,5 \mu \mathrm{g} / \mathrm{ml}$ cholesterol, $0.01 \mathrm{M}$ potassium citrate, $\mathrm{pH} 6,0.05 \mathrm{mM}$ EDTA, $0 \cdot 025 \mu \mathrm{M} \mathrm{FeSO}_{4} \cdot 7 \mathrm{H}_{2} \mathrm{O}, 0 \cdot 01 \mu \mathrm{M} \mathrm{MnCl}{ }_{2} \cdot 4 \mathrm{H}_{2} \mathrm{O}, 0 \cdot 01 \mu \mathrm{M}$ $\mathrm{ZnSO}_{4} \cdot 7 \mathrm{H}_{2} \mathrm{O}, 0 \cdot 001 \mu \mathrm{M} \mathrm{CuSO}_{4} \cdot 5 \mathrm{H}_{2} \mathrm{O}, 3 \mathrm{mM} \mathrm{CaCl}$, $3 \mathrm{mM} \mathrm{MgSO}$ ) supplemented with $7 \boldsymbol{g}$ E. coli strain NA22 paste. Cultures were continuously shaken at 250 r.p.m. for 4-5 days. Worms were then harvested in $200 \mathrm{ml}$ centrifuge bottles, kept on ice for $30 \mathrm{~min}$, and centrifuged for $5 \mathrm{~min}$ at $300 \mathrm{~g}$ at $4{ }^{\circ} \mathrm{C}$. The resulting pellet (usually $5-10 \mathrm{ml}$ ) was

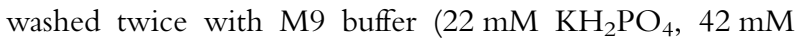
$\left.\mathrm{Na}_{2} \mathrm{HPO}_{4}, 86 \mathrm{mM} \mathrm{NaCl}, 1 \mathrm{mM} \mathrm{MgSO} 4\right)$. The worms were finally washed with $0 \cdot 1 \mathrm{M} \mathrm{NaCl}$ and then resuspended in $20 \mathrm{ml} 0 \cdot 1 \mathrm{M} \mathrm{NaCl}$, mixed with $20 \mathrm{ml} 60 \%$ (w/v) sucrose, and centrifuged for $3 \mathrm{~min}$ at $300 \mathrm{~g}$ at $4{ }^{\circ} \mathrm{C}$. Floating worms were recovered and washed twice in $0 \cdot 1 \mathrm{M} \mathrm{NaCl}$.

\section{Isolation of let-767 $c D N A, 5^{\prime}-R A C E$, and construction of pCMVneo-Let 767}

The EST clone yk475a10 was kindly provided by Dr Yuji Kohara (National Institute of Genetics, Mishima, Japan). To determine the true $5^{\prime}$-end cDNA, as well as the trans-splicing nature of let-767 mRNA, PCR was performed on an oligo(dT)-primed cDNA library made from poly $(\mathrm{A})^{+}{ }^{+} \mathrm{RNA}$ from mixed-stage worm culture (see RNA preparation below). PCR amplifications were performed using splice leader 1 (SL1) primer (5'-GTT-TAA-TTA-CCC-AAG-TTT-GAG-3'), SL2 primer (5'-GGT-TTT-AAC-CCA-GTT-ACT-CAA-G-3'), or a gene-specific primer (GSP1; 5'-ATG-GCT-TGC-CAGTGC-TTC-TTG-3') as forward primers and a gene-specific reverse primer (GSP2) (5'-GCG-AGA-AGA-TCT-TTGTAA-GCA-3 ${ }^{\prime}$ ). The distance between GSP1 and GSP2 is 359 bp. The PCR conditions using the Phusion High-Fidelity DNA polymerase (New England Biolabs, Ontario, Canada) were as follows: first, a denaturing step at $94^{\circ} \mathrm{C}$ for $90 \mathrm{~s}$; second, a step at $98^{\circ} \mathrm{C}$ for $10 \mathrm{~s}$ followed by a step at $55^{\circ} \mathrm{C}$ for $10 \mathrm{~s}$ repeated 25 times; and a final step at $72{ }^{\circ} \mathrm{C}$ for $5 \mathrm{~min}$. The PCR products were sequenced using an automated dideoxynucleotide DNAsequencing using the Big Dye Terminator v3.1 Cycle Sequencing (ABI Prism, Applied Biosystems, Foster City, CA, USA) as described previously (Liu et al. 2007). It appeared that the sequence of $\mathrm{yk} 475 \mathrm{a} 10$ contained the entire coding region of let-767. The cDNA fragment of let-767 was then excised from the EST and inserted into a pCMVneo vector downstream from a cytomegalovirus promoter, at the Eco RI and Kpn I restriction sites. The resulting pCMVneo-Let767 vector was sequenced to verify its integrity and stably transfected into HEK-293 cells as described previously (Liu et al. 2007).

\section{$R N A$ preparation}

Total RNA was prepared from frozen worm pellets by first pulverizing them in a mortar with liquid nitrogen and then homogenizing the resulting powder with a polytron in a sonicating buffer $(500 \mathrm{mM} \mathrm{NaCl}, 200 \mathrm{mM}$ Tris-Cl, $\mathrm{pH} 7 \cdot 5$, $10 \mathrm{mM}$ EDTA, $1 \%$ SDS, $100 \mathrm{mM} \beta$-mercaptoethanol). An equal volume of phenol ( $\mathrm{pH} \mathrm{4.3)}$ was added to extract RNA. The aqueous phase was further treated (three to five times) with an equal volume of phenol/chloroform/isoamyl alcohol $(125: 24: 1, \mathrm{pH} 4 \cdot 3)$ to remove protein. Total RNA was precipitated by addition of $0 \cdot 1$ volume of $3 \mathrm{M} \mathrm{NaOAc}(\mathrm{pH}$ $5 \cdot 2$ ) and 2 volumes of $100 \%$ ethanol, and incubation at $-75^{\circ} \mathrm{C}$. Poly(A) + RNA was extracted from total RNA by a poly(dT)column using an mRNA purification kit (Pharmacia). 


\section{dsRNA-induced phenotype}

Forward and reverse RNA strand encoding LET-767 were synthesized using T3 and T7 promoters of the EST clone yk475a10 and the Ribomax RNA synthesis kit (Promega). The two single-stranded RNAs were annealed to form dsRNA and injected as described previously (Fire et al. 1998). Microinjected worms (dsRNA or buffer) were allowed to lay eggs for a period of $16 \mathrm{~h}$. Ten egg-laying hermaphrodites were placed individually on fresh plates. They were allowed to lay eggs until there were about 30 embryos on the plates. Then, the egg-laying hermaphrodites were removed from the plates. Photographs of the F1 progeny were taken every $12 \mathrm{~h}$ using a Photometrics CoolSnap Fx camera attached to a Nikon E1000 microscope. $\mathrm{N} 2$ worms (not injected) were synchronized using the bleaching technique (Hope 1999). Eggs were placed on an NGM plate with OP50 bacteria. Photographs were taken every $12 \mathrm{~h}$.

\section{Sequencing of let- 767 alleles}

To identify nucleotide changes in LET-767 lethal mutants, cDNA encoding LET-767 was amplified by PCR on homozygous $d p y-17$ let-767 (s2176) unc-32, dpy-17 let-767 (s2819) unc-32, and $d p y-17$ let-767 (s2464) unc-32. The primers used were 5'-TAG-TTA-CAA-GAA-ATA-ATG-GAGTCG-T- $3^{\prime}$ as forward primer and $5^{\prime}$-TGA-AGC-ATT-GTTGGG-TTA-CTG-T- $3^{\prime}$ as reverse primer. The amplified PCR products were sequenced using an automated dideoxynucleotide DNAsequencing using the Big Dye Terminator v3.1 Cycle Sequencing (ABI Prism, Applied Biosystems), and the following primers: $\quad 5^{\prime}$-TAG-TTA-CAA-GAA-ATA-ATG-GAGTCG-T-3', 5'-TGA-AGC-ATT-GTT-GGG-TTA-CTGT-3', 5'-CTC-GAG-AAG-TAT-TCC-AGC-ATT-GAG-3', and $5^{\prime}$-ACG-GAG-CCG-TGT-TCG-CTA-AAT-C-3'.

\section{Amino acid substitution using site-directed mutagenesis}

Amino acid substitution on the LET-767 expression vector was performed as described previously (Dufort et al. 1999) using the Quick Change Site-directed Mutagenesis kit (Stratagene, La Jolla, CA, USA) and the following primer pairs: $5^{\prime}$-CAT-GCT-CCC-TTG-GCC-ACT-CTT-GAC-3' and 5'-GTG-TCC-TGC-CAT-ACG-CCG-TAG-CTACAA-AAC-T- $3^{\prime} ; \quad 5^{\prime}$-CCC-TGT-TTC-CTG-TGC-CTCTCT-ACT-C- $3^{\prime}$ and $5^{\prime}-\mathrm{GTG}-\mathrm{CTG}-\mathrm{ACC}-\mathrm{CCA}-\mathrm{TAT}-\mathrm{TTT}-$ GTC-TCG-ACT-GCA-ATG-3'; 5'-ACC-GGA-GCCACT-GAC-GAA-ATC-GGA-AAA-GCA-TAC- $3^{\prime}$ and $5^{\prime}-$ ACC-GGA-GCC-ACT-GAC-GAA-ATC-GGA-AAAGCA-TAC-3 ${ }^{\prime} ; 5^{\prime}$-CTT-ATT-AAC-AAC-GTT-AGA-ATGAGC-TAC-GAA-TAT- $3^{\prime}$ and $5^{\prime}$-CTT-ATT-AAC-AACGTT-AGA-ATG-AGC-TAC-GAA-TAT- ${ }^{\prime}$; and $5^{\prime}$-GTCGCA-CGA-AAG-GCT-AGA-GTC-ATT-GTT-AAT-GTT$3^{\prime}$ and $5^{\prime}$-GTC-GCA-CGA-AAG-GCT-AGA-GTC-ATTGTT-AAT-GTT-3'. These primers allowed to make the amino acid M234F, M234A, G58E, G135R, and G182R substitutions respectively. The integrity of the constructs was verified by sequencing of the inserted DNA fragment. Plasmid DNA was prepared using the Qiagen Mega Kit (Qiagen). Oligonucleotide primers were synthesized with a DNA synthesizer ABI-394 (Perkin-Elmer-Cetus, Emerville, CA, USA).

\section{Enzymatic assay}

Determination of the activity was performed in transiently transfected intact cells in culture as previously described (Dufort et al. 1999). Briefly, cells were plated into 6-well plates at a density of $5 \times 10^{5}$ cells/well in MEM (Invitrogen Canada Inc.) supplemented with $10 \%$ (v/v) calf fetal serum (Hyclone, Logan, UT, USA) at $37{ }^{\circ} \mathrm{C}$ under a $95 \%$ air $/ 5 \%$ $\mathrm{CO}_{2}$ humidified atmosphere. Five micrograms of pCMVneoplasmid containing cDNA insert encoding LET-767 as well as LET-767 mutants were transfected into cells using ExGen 500 transfection kit as indicated by the manufacturer (Fermentas Canada Inc., Burlington,ON, Canada). A mock transfection was performed as control with the expression vector pCMVneo without insert. After 16-h incubation, the transfection medium was removed and $2 \mathrm{ml} \mathrm{MEM} \mathrm{culture}$ medium were added. $0 \cdot 1 \mu \mathrm{M}$ of the indicated ${ }^{14} \mathrm{C}$-labeled steroid (Dupont Inc., Mississauga, Canada) were added to freshly changed MEM culture medium and incubated for $24 \mathrm{~h}$. After incubation, steroids were extracted twice with $1 \mathrm{ml}$ ether. The organic phases were pooled and evaporated to dryness. The resulting dry steroids were solubilized in $50 \mu \mathrm{l}$ dichloromethane and applied onto Silica Gel 60 TLC plates (Merck) before separation by migration using a toluene:acetone $(4: 1)$ solvent system. Substrates and metabolites were identified by comparison with reference steroids, and quantified using the PhosphorImager System (Molecular Dynamics Inc., Sunnyvale, CA, USA).

\section{Results}

Mutational analysis of let-767 and transcripts trans-splicing

Let-767 is known to be essential for the worm development (Kuervers et al. 2003). The three alleles that confer developmental arrest and lethality $(s 2176, s 2819$, and s2464) were originally isolated from screens performed by Dr David Baillie's group (Stewart et al. 1998, Vatcher et al. 1999). These alleles have been genetically characterized and are referred to as early larval lethal for $s 2176$, mid-larval lethal for $s 2819$, and maternal effect lethal for $s 2464$ (Kuervers et al. 2003). Only the $s 2176$ was characterized at the molecular level. It was shown to be a missense mutation replacing the guanine 403 for an adenine, which changes the G135 to R (G135R) (Fig. 1B and Kuervers et al. (2003)). In order to further characterize the $s 2819$ and the s2464 alleles, we sequenced the entire let-767 genes isolated from homozygous mutants by single worm PCR. The sequences obtained revealed that $s 2819$ and s2464 have missense mutations (Fig. 1A and B). The mutation in s2819 replaces guanine 544 for an adenine, which changes G182 to $\mathrm{R}$ 


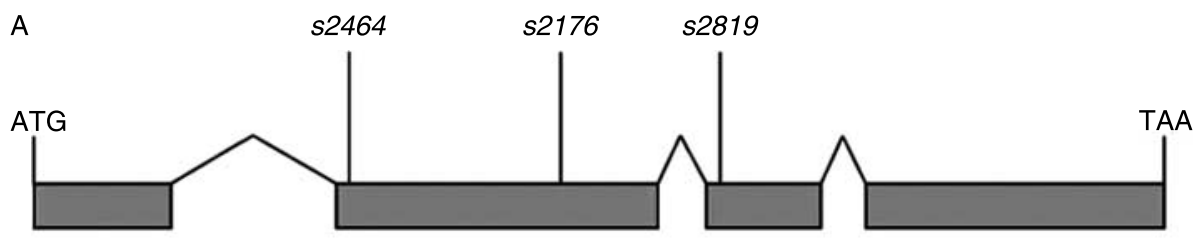

$100 \mathrm{bp}$

B

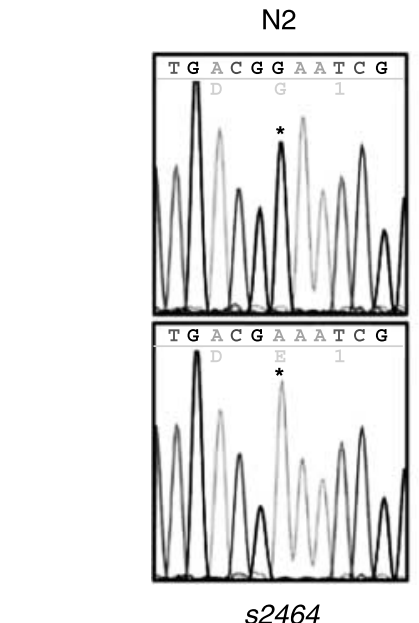

(G58E)
$\mathrm{N} 2$

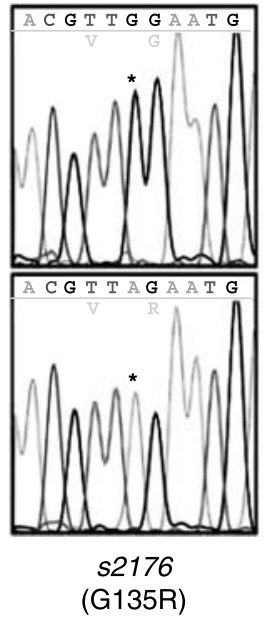

N2

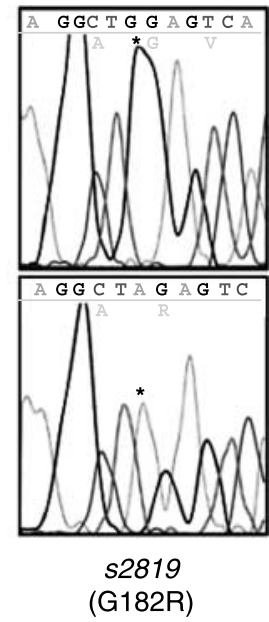

C

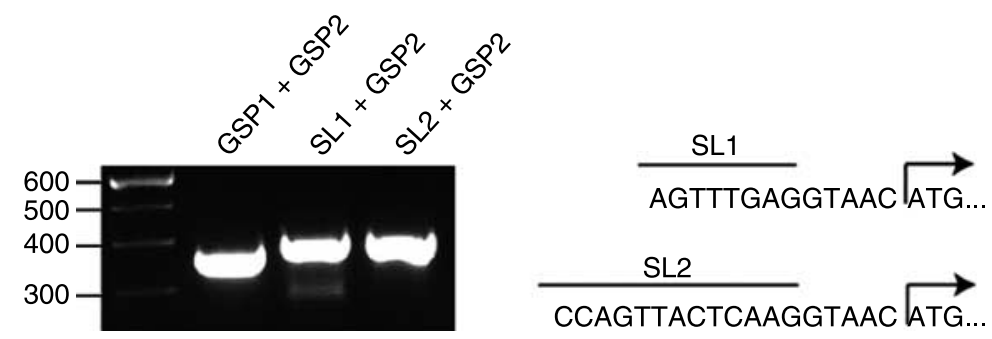

Figure 1 let-767 Gene structure, mutational analysis, and trans-splicing structure. (A) Structure of let-767. Exons are boxed, introns are represented by lines. ATG and TAA represent start and stop codons respectively. (B) Nucleotide sequence illustrating the nucleotide changes in s2464, s2176, and s2819 compared with the wild-type N2 sequences (upper panels). The amino acid substitutions are indicated in parentheses.

(C) Evidence that the mRNA of let-767 is trans-spliced with SL1 or SL2. DNA fragments obtained by PCR amplification using gene-specific primer 1 (GSP1) that starts at the start codon and GSP2 that is $359 \mathrm{bp}$ downstream of the start, as well as the splice leader 1 (SL1) primer or the SL2 primer as forward primer and GSP2 as the reverse primer were separated on agarose gel electrophoresis. Specific bands were excised from the gel and their sequence was determined by automated sequencing. The partial sequences obtained for SL1 and SL2 are shown along with an untranslated sequence (GTAAC) and the start codon ATG.

(G182R). Likewise, s2464 has guanine 173 changed to an adenine, which changes $\mathrm{G} 58$ to $\mathrm{E}$ (G58E).

It has been reported that the expression profile of let-767 is uniform throughout the life cycle of the worm, thus it is expressed at all developmental stages, and that transcripts are either not trans-spliced or trans-spliced with SL1 (Wormbase web site, http://www.wormbase.org, release WS159, June 22, 2006). Our observation shows that part of the let-767 transcripts are also trans-spliced by SL2 (Fig. 1C). The exact significance of this peculiar trans-splicing status is not known.
However, the $5^{\prime}$-RACE analysis provides evidence about the true nature of the $5^{\prime}$ structure of the let-767 transcripts. It shows that the start codon is 51 nucleotides downstream from what was suggested earlier (Kuervers et al. 2003).

Effect of RNA interference (RNAi) of let-767 expression on the development of $\mathrm{C}$. elegans

To assess the function of let-767, we performed an RNAi experiment using the coding sequence of let-767. As shown 
N2
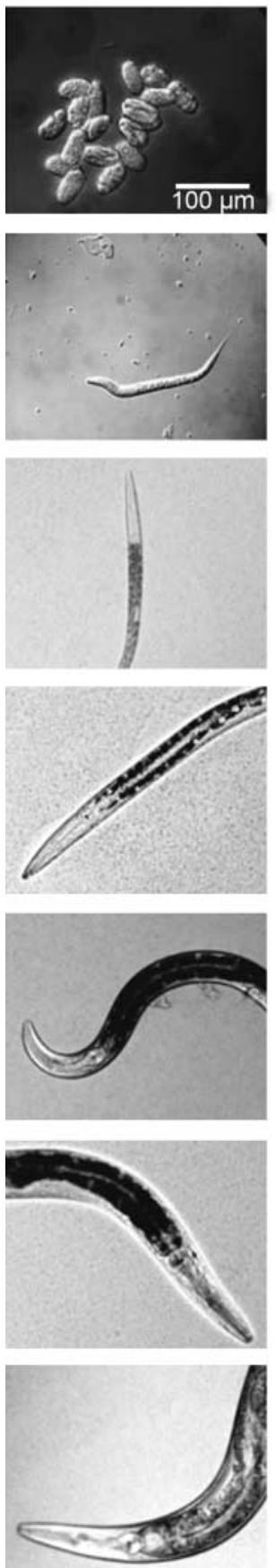

Buffer
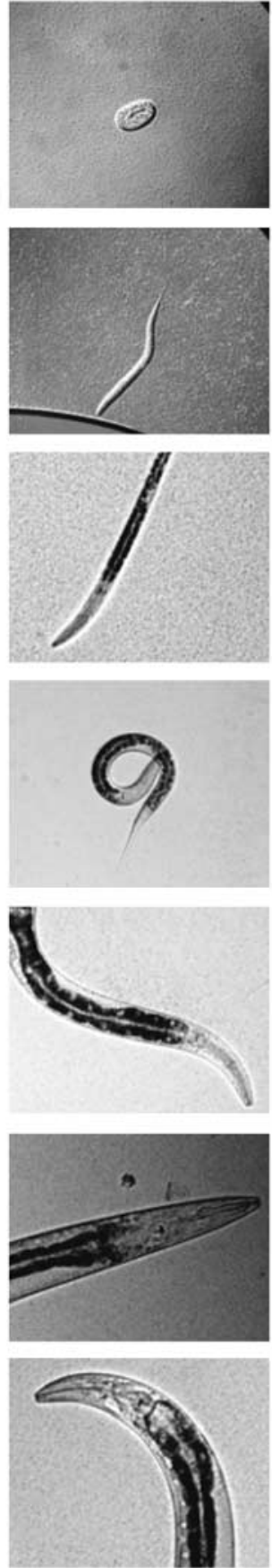

let-767 (RNAi)

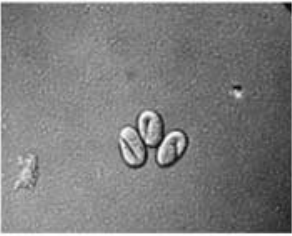

$\mathrm{Oh}$

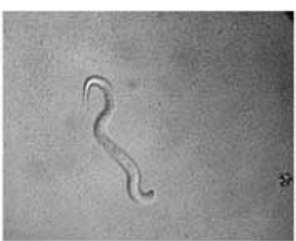

$12 \mathrm{~h}$

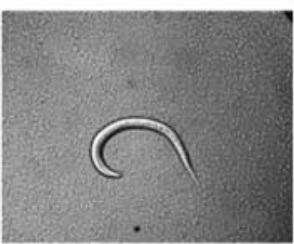

$24 \mathrm{~h}$

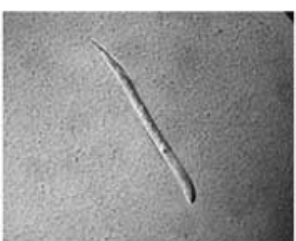

$36 \mathrm{~h}$

$48 \mathrm{~h}$

$60 \mathrm{~h}$

$72 \mathrm{~h}$

Figure 2 Silencing of let-767 by RNAi induces developmental arrest. N2 wild-type worms were either not injected (N2), injected with microinjection buffer (Buffer), or injected with let-767 dsRNA (let-767 (RNAi)). The $\mathrm{F}_{1}$ progeny was followed throughout their entire life cycle until they reached adulthood, and photographs were taken every $12 \mathrm{~h}$, the period of time roughly equivalent to a developmental stage. Worms injected with dsRNA from let-767 display a developmental arrest phenotype. L: larval stage. 
in Fig. 2, N2 worms injected with dsRNA covering the entire coding sequence of let-767 stop their development at the first larval-second larval (L1-L2) stages, whereas wildtype N2 worms not injected with dsRNA or injected with microinjection buffer alone progress normally through all developmental stages. This is in agreement with the observation that alleles $s 2176, s 2819$, and $s 2464$ confer a null phenotype in the form of early larval arrest (Kuervers et al. 2003).

LET-767 catalyzes efficiently the transformation of androstenedione and estrone into testosterone and estradiol in transfected cells respectively

Sequence alignment (Fig. 3) shows that let-767 shares similar consensus amino acid sequences for cofactor and active site with human $17 \beta-$ HSD3 and 12 . To determine whether C. elegans LET-767 is able to catalyze the conversion of androstenedione and estrone into testosterone and estradiol such as human $17 \beta-$ HSD 3 and 12 respectively, we cloned the coding region of let-767 cDNA into a mammalian expression vector, pCMVneo (12), and introduced it into HEK-293 cells by transient transfection. As shown in Fig. 4, cells transfected with an expression vector lacking a cDNA insert (Mock) display no measurable conversion of 4-androstenedione into testosterone and estrone into estradiol. On the other hand, in the presence of the cDNA insert encoding let-767, high conversion of 4-androstenedione into testosterone and estrone into estradiol has been observed, thus indicating that LET-767 is able to convert androgen as well as estrogen substrates. The situation is similar to that observed with the mouse 17 $\beta$-HSD12 (Blanchard \& Luu-The 2007) that possesses a small size amino acid (L) at position 234. In human, 17 $\beta$-HSD12 (Luu-The et al. 2006) has lost the ability to metabolize androgen that is produced by the isoform $17 \beta$ HSD3 (Geissler et al. 1994). The presence of $17 \beta-H S D 3$ in the mouse and human, which catalyzes the formation of testosterone in the testis, suggests that the mouse 17 $\beta$-HSD12 is rather implicated in the biosynthesis of estrogen although it has the ability to convert androgen substrate.

\begin{tabular}{|c|c|c|}
\hline LET -767 & MACQCFLVGAGYVALAA *VAYRLITI * FSNILGPYVLLSPIDLKKRAGA * & 47 \\
\hline h17 $\beta-\mathrm{HSD} 12$ & -ESALPAA - FL-WVG-GT- - - LA-R-SY - LFTALR-WGVGNEAGVGP - LG & o \\
\hline h17 1 -HSD3 & -GDVL*EQFFILTG-LVCL-CLAKCVRF - RCVLLNYWKVLPKSFL-S*MG & \\
\hline $\mathrm{LET}-767$ & SWAVVTGATDGIGKAYAFELARRGFNVLLVSRTQSKLDETKKEILEKYSSI & \\
\hline h17 $\beta-H S D 12$ & 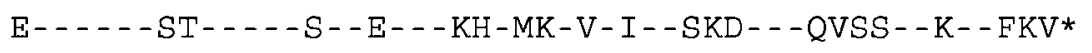 & 0 \\
\hline h17 1 -HSD3 & $\mathrm{Q}---\mathrm{I}---\mathrm{G}-------\mathrm{S}----\mathrm{K}--\mathrm{L}-\mathrm{V}-\mathrm{I}---\mathrm{LE}--\mathrm{EAIAT}--\mathrm{ERTTGR} *$ & \\
\hline $\mathrm{LET}-767$ & EVRTAAFDFTNAAPSAYKDLLATLNQVEIGVLINNVGMSYEYPDVLHKVDG & \\
\hline h17 $\beta-\mathrm{HSD} 12$ & $-\mathrm{T}--\mathrm{I}-\mathrm{V}--\mathrm{A} *$ *SEDI-DKIKTG-AGL- - I-V- - - - - - EYFLD - PD & \\
\hline $\mathrm{h} 17 \beta-\mathrm{HSD} 3$ & S-KIIQA - - * * KDDI - EHIKEK-AGL-- - I -V- - - - LPNLLPSHFLNAP & \\
\hline $\mathrm{LET}-767$ & GIERLANITTINTLPPTLLSAGILPQMVARKAGVIVNVGSSAGANQMALW & \\
\hline $\mathrm{h} 17 \beta-\mathrm{HSD} 12$ & LDNVIKKMIN- - ILSVCKMTQLV- -G- - E-SK-A- L- IS-GS-MLPVP-L & 199 \\
\hline h17 $17-\mathrm{HSD} 3$ & D* - * IQSLIHC-ITSVVKMTQL- - KH - ES-QK-L-L-IS-GIALFPWP - Y & \\
\hline $\mathrm{LET}-767$ & AVYSATKKYVSWLTAILRKEYEHQGITVQTIAPMMVATKMSKVKRTSFFT & 24 \\
\hline h17 $\beta-\mathrm{HSD} 12$ & TI-----TF-DFFSQC-HE--RSK-VF- - SVL- - F- - - LA - IRKPTLDK & 24 \\
\hline h17 $\beta-\mathrm{HSD} 3$ & $\mathrm{SM}---\mathrm{S}-\mathrm{AF}-\mathrm{CAFSKA}-\mathrm{QE}--\mathrm{KAKEVII}-\mathrm{VLT}--\mathrm{A}-\mathrm{S}-\mathrm{A}-\mathrm{T}-\mathrm{YLN}-\mathrm{NVI}-$ & 24 \\
\hline LET- 767 & PDGAVFAKSALNTVGNTSDTTGYITHQLQLELMDI I PTFIRDKILTNMSV & \\
\hline h17 $\beta-\mathrm{HSD} 12$ & -SPET-V- - - IK- - - LQ-R-N- - LI - A-MGSIISNL - SW-YL- -VM- -NK & 29 \\
\hline $\mathrm{h} 17 \beta-\mathrm{HSD} 3$ & KTADE-V-ES- -Y-TIGGE-C-CLA-EILAGFLS- - -AWAFYSGAFQRLL & \\
\hline $\mathrm{LET}-767$ & GTRAAALRKKEREAKSQ & \\
\hline h17 $\beta-H S D 12$ & $\mathrm{~S}---\mathrm{HY}-*--* * \mathrm{TK}-\mathrm{N} *$ & \\
\hline$\beta-\mathrm{HSD} 3$ & L- * * HYVAYLKLNT - VR & \\
\hline
\end{tabular}

Figure 3 Comparison of amino acid sequences of LET-767, 17 $\beta$-HSD12, and 17 $\beta$-HSD3. Amino acids are presented in conventional single-letter code and numbered on the right. Dashes $(-)$ and dots $(*)$ represent identical and missing amino acids respectively. The consensus sequences for cofactor binding and active sites are underlined. 


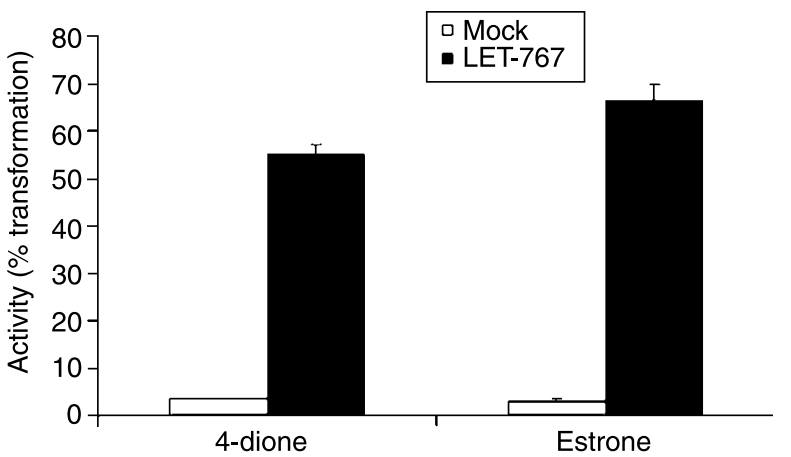

Figure 4 Conversion of 4-androstenedione and estrone by LET-767. The experiments were performed using transiently transfected cells in culture containing $0 \cdot 1 \mu \mathrm{M}$ of the indicated ${ }^{14} \mathrm{C}$-labeled androstenedione and estrone. 4-Dione, conversion of 4-androstenedione into testosterone; Estrone, conversion of estrone into estradiol. Hundred percent conversion represents 34 and 35 pmoles/h per $10^{6}$ cells for the conversion of 4-dione and Estrone respectively. The incubation of control HEK-293 cells with the same substrates serves as control. The data are expressed as means \pm s.E.M. of triplicate measurements.

\section{Role of M234 in substrate preference}

Previously (Luu-The et al. 2006), we have shown that the amino acid F234 in human 17ß-HSD12 is responsible for the estrogen selectivity. Using 3D-structure modeling and site-directed mutagenesis, we have shown that the large size of $\mathrm{F}$ in $17 \beta$-HSD1 2 could prevent $\mathrm{C} 19$-steroid from entering the active site by steric hindrance, while the smaller size of $\mathrm{A}$, the corresponding amino acid in type $317 \beta-\mathrm{HSD}$, permits the entrance of androgen (Luu-The et al. 2006). As illustrated in the amino acid sequence alignment of LET-767 with $17 \beta$-HSD3 and 12 (Fig. 3), the corresponding amino acid at this position in C. elegans is M234. To determine whether the smaller size of $\mathrm{M}$ compared with $\mathrm{F}$ could be responsible for the ability of LET-767 to metabolize 4-androstenedione as

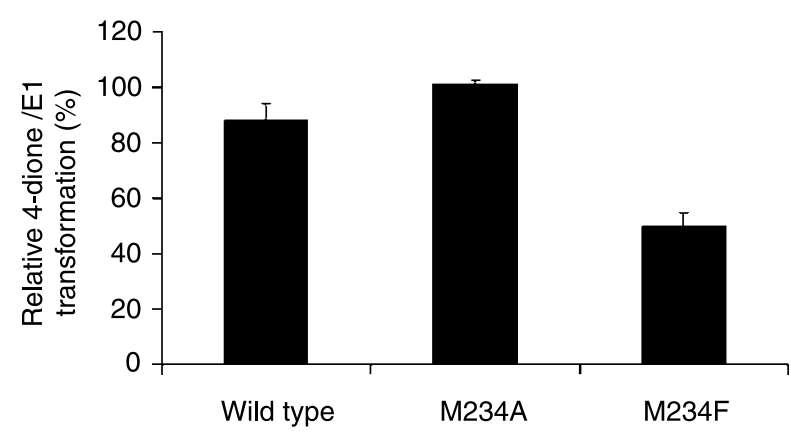

Figure 5 Effects of M234F and M234A amino acid substitutions on LET-767 activity. HEK-293 cells were transiently transfected with expression vectors encoding LET-767 (wild-type) and mutants with a substitution of $\mathrm{M}$ at position 234 for $\mathrm{F}$ (M234F) or $\mathrm{A}$ (M234A). The ability of transfected cells to convert estrone into estradiol and 4-androstenedione into testosterone was determined as described in Materials and Methods. The data are expressed as means \pm S.E.M. of triplicate measurements. E1, estrone well as estrone (Fig. 4), we performed an M234F substitution. As expected, the ability of the mutated enzyme to transform 4-androstenedione, compared with the transformation of estrone, is much lower than that observed with the wild-type and M234A substitution (Fig. 5).

Effect of lethal mutations in let-767 on the ability to metabolize 4-androstenedione and estrone

As mentioned above, there are three lethal point mutations in let- 767 that change $\mathrm{G}$ at positions 58,135 , and 182 into $\mathrm{E}, \mathrm{R}$, and $R$ respectively. To determine how these amino acid substitutions affect LET-767 enzymatic activity, we have substituted these amino acids in LET-767 expression vectors by site-directed mutagenesis, as described in Materials and Methods. As shown in Fig. 6, all three mutations, G58E, G135R, and G182R, inactivate the transformation of 4-androstenedione to testosterone (Fig. 6A), as well as the transformation of estrone into estradiol (Fig. 6B). These results suggest that there is a strong relationship between development of lethal mutations and the ability to metabolize androgen and estrogen by LET-767.
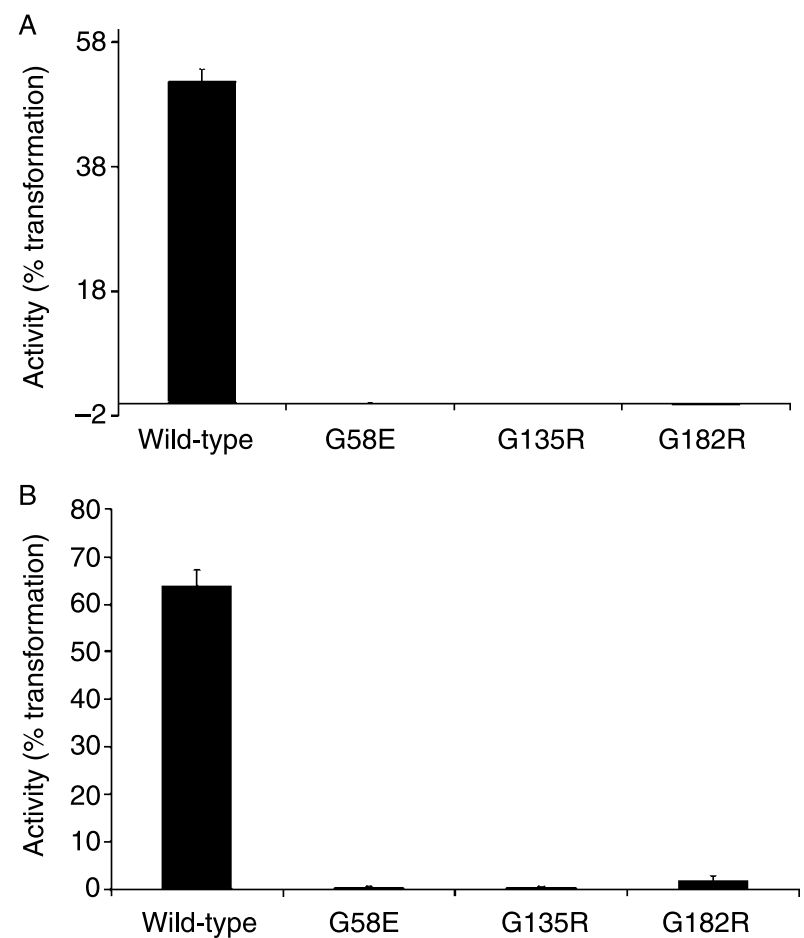

Figure 6 Effects of substitution with amino acids from lethal mutants on LET-767 activity. HEK-293 cells were transiently transfected with expression vectors encoding LET-767 (wild-type) and mutants containing G58E, G135R, and G182R substitutions. The ability of transfected cells to convert 4-androstenedione into testosterone (A) and estrone into estradiol (B) were determined as described in Materials and Methods. The data are expressed as means \pm S.E.M. of triplicate measurements. 


\section{Discussion}

In this paper, we show that let-767 in C. elegans encodes a homolog of human $17 \beta-$ HSD3 and 12, the two enzymes involved in the formation of testosterone (Geissler et al. 1994) and estradiol (Luu-The et al. 2006), a key natural androgen and estrogen respectively. However, in contrast with the human enzymes that show substrate specificity, LET-767 catalyzes the transformation of 4-androstenedione into testosterone as well as estrone into estradiol, similar to that found in the mouse 17ß-HSD12 (Blanchard \& Luu-The 2007). Previously, we have shown that the amino acid F234 is responsible, in part, for the androgenic-estrogenic substrate specificity. Mutational study of the corresponding amino acid in C. elegans (M234; Fig. 5) confirms the ability of this amino acid to control the entrance of C19- or C18-steroid into the active site. The conserved amino acid position responsible for androgenestrogen selectivity as well as the conserved amino acid sequence for active and cofactor binding sites strongly suggests that let-767 shares a common ancestor with $17 \beta-$ HSD12 and its duplicate type $317 \beta-H S D$ gene. In human and primates, $17 \beta-H S D 3$ and 12 diverge and acquire substrate specificity for androgen and estrogen respectively. In the mouse, it is likely that androgen-estrogen selectivity is less critical than in human, since many estrogen-selective $17 \beta-$ HSDs in human such as $17 \beta-H S D 1$ and 12 catalyze as well the production of androgens (Nokelainen et al. 1996, Blanchard \& Luu-The 2007 ). It is noteworthy that $17 \beta-$ HSD 3 is responsible for the formation of testosterone, one of the key steroid hormones. The gene is specifically expressed in the human testis and its deficiency is responsible for male pseudohermaphroditism in young boys (Geissler et al. 1994) that affects the formation of the internal male reproductive structures (epididymides, seminal vesicles, and vas deferens) as well as the initiation and maintenance of spermatogenesis and the development and maintenance of secondary male characteristics, such as voice deepening and muscle strength (Wilson 1978). This could be related to the mutations of let-767 (alleles s2176, s2819, and s2464) that affect the production of steroid hormone in $C$. elegans responsible for developmental arrest leading to early larval, mid-larval, and maternal effect lethalities (Kuervers et al. 2003). Using site-directed mutagenesis (Fig. 6A and B), we have also shown a strong relationship between these lethal mutations and the ability to metabolize androgen and estrogen and most probably the active hormone in C. elegans.

It is noteworthy that all the point mutations involve a glycine codon. This is not surprising since all $\mathrm{G}$ codons have at least two guanines and that the mutagen used to generate these mutations is ethyl methanesulfonate (EMS), a chemical known to preferentially attack guanines (Singer \& Kusmierek 1982). It is even more important to note that all the missense mutations involve conserved $\mathrm{G}$ (Fig. 3). $\mathrm{G}$ is a non-polar amino acid. Mutational changes to a basic amino acid such as $\mathrm{R}$ or an acidic amino acid such as $\mathrm{E}$ is predictive of profound changes regarding the structure and/or the function of the encoded protein.
Similar to LET-767 that is able to metabolize vertebrate hormone androgen and estrogen, it has been shown that the plant enzyme responsive for det 2 mutation, which causes small dark green dwarfs to display pleiotropic defects in lightregulated development during multiple stages of the Arabidopsis plant life cycle, is also able to convert vertebrate steroid hormone testosterone into dihydrotestosterone although its natural plant steroid hormone is campestanol, a brassinosteroid ( $\mathrm{Li}$ et al. 1997). It is noteworthy that the human type $25 \alpha$-reductase is also able to convert campesterol into campestanol and it is identified as ortholog of det 2 in plant (Li et al. 1997). The similarity between the two cases, LET-767/17 $\beta$-HSD 12 and $\operatorname{det} 2 / 5 \alpha$-reductase, suggests that LET-767 is involved in the biosynthesis of the active steroid in C. elegans that has a structure different from sex steroids in mammals but it could play an equivalent role.

The present data show that LET-767 is able to metabolize the same substrate as human $17 \beta-H S D 3$ and 12 enzymes and it also contains the amino acid involved in the substrate selectivity. These data strongly suggest that LET-767 could be used as a model for studying the structure-activity relationship of $17 \beta-$ HSD3 and 12 . It could also help in designing specific inhibitors for these enzymes, which represent interesting drug targets, for the treatment of androgen- and estrogen-sensitive diseases.

\section{Acknowledgements}

We thank Dr Yuji Kohara for providing us with EST clone yk475a10, Guy Remnitz for his skillful technical assistance, and Bob Johnsen for comments. This work is partially supported by The Foundation for Research into Children's Diseases. J -F, St-L, and P $-\mathrm{G}$ B were supported by studentships from the Fonds de la Recherche en Santé du Québec. D L B holds a Canadian Research Chair and is supported by grants from Natural Sciences and Engineering Research Council of Canada (NSERC Canada) and Canadian Institutes of Health Research (CIHR). S D is a Junior 2 Research Fellow from the Fonds de la Recherche en Santé du Québec. Part of this work was supported by CIHR grant MOP-77698 to V L T. The authors declare that there is no conflict of interest that would prejudice the impartiality of this scientific work.

\section{References}

Baker ME 2003 Evolution of adrenal and sex steroid action in vertebrates: a ligand-based mechanism for complexity. BioEssays 25 396-400.

Bertrand S, Brunet FG, Escriva H, Parmentier G, Laudet V \& RobinsonRechavi M 2004 Evolutionary genomics of nuclear receptors: from twenty-five ancestral genes to derived endocrine systems. Molecular Biology and Evolution 21 1923-1937.

Blanchard P-G \& Luu-The V 2007 Differential androgen and estrogen substrates specificity in the mouse and primates type 1217 -hydroxysteroid dehydrogenase. Journal of Endocrinology 194 449-455. 
Dufort I, Rheault P, Huang X-F, Soucy P \& Luu-The V 1999 Characteristics of a highly labile human type 5 17beta-hydroxysteroid dehydrogenase. Endocrinology 140 568-574.

Fire A, Xu S, Montgomery MK, Kostas SA, Driver SE \& Mello CC 1998 Potent and specific genetic interference by double-stranded RNA in Caenorhabditis elegans. Nature 391 806-811.

Geissler WM, Davis DL, Wu L, Bradshaw KD, Patel S, Mendonca BB, Elliston KO, Wilson JD, Russell DW \& Andersson S 1994 Male pseudohermaphroditism caused by mutations of testicular 17 beta-hydroxysteroid dehydrogenase 3. Nature Genetics 7 34-39.

Hope I 1999 C. elegans: A Practical Approach., Oxford: Oxford University Press.

Kuervers LM, Jones CL, O’Neil NJ \& Baillie DL 2003 The sterol modifying enzyme LET-767 is essential for growth, reproduction and development in Caenorhabditis elegans. Molecular Genetics and Genomics 270 121-131.

Labrie F, Luu-The V, Lin SX, Labrie C, Simard J, Breton R \& Belanger A 1997 The key role of 17 beta-hydroxysteroid dehydrogenases in sex steroid biology. Steroids 62 148-158.

Labrie F, Luu-The V, Lin SX, Simard J \& Labrie C 2000 Role of 17 betahydroxysteroid dehydrogenases in sex steroid formation in peripheral intracrine tissues. Trends in Endocrinology and Metabolism 11 421-427.

Li J, Biswas MG, Chao A, Russell DW \& Chory J 1997 Conservation of function between mammalian and plant steroid 5alpha-reductases. PNAS 94 3554-3559.

Liu H, Zheng S, Bellemare V, Pelletier G, Labrie F \& Luu-The V 2007 Expression and localization of estrogenic type 12 17beta-hydroxysteroid dehydrogenase in the cynomolgus monkey. BMC Biochemistry 82 .

Luu-The V 2001 Analysis and characteristics of multiple types of human 17ß-hydroxysteroid dehydrogenases. Journal of Steroid Biochemistry and Molecular Biology 76 143-151.
Luu-The V, Tremblay P \& Labrie F 2006 Characterization of type 12 17betahydroxysteroid dehydrogenase, an isoform of type 3 17beta-hydroxysteroid dehydrogenase responsible for estradiol formation in women. Molecular Endocrinology 20 437-443.

Merris M, Wadsworth WG, Khamrai U, Bittman R, Chitwood DJ \& Lenard J 2003 Sterol effects and sites of sterol accumulation in Caenorhabditis elegans: developmental requirement for 4alpha-methyl sterols. Journal of Lipid Research 44 172-181.

Mindnich R, Moller G \& Adamski J 2004 The role of 17 beta-hydroxysteroid dehydrogenases. Molecular and Cellular Endocrinology 218 7-20.

Nokelainen P, Puranen T, Peltoketo H, Orava M, Vihko P \& Vihko R 1996 Molecular cloning of mouse 17 beta-hydroxysteroid dehydrogenase type 1 and characterization of enzyme activity. European Journal of Biochemistry 236 482-490.

Singer B \& Kusmierek JT 1982 Chemical mutagenesis. Annual Review of Biochemistry 51 655-693.

Stewart HI, O’Neil NJ, Janke DL, Franz NW, Chamberlin HM, Howell AM, Gilchrist EJ, Ha TT, Kuervers LM, Vatcher GP et al. 1998 Lethal mutations defining 112 complementation groups in a $4.5 \mathrm{Mb}$ sequenced region of Caenorhabditis elegans chromosome III. Molecular Genetics and Genomics 260 280-288.

Vatcher GP, Barbazuk WB, O’Neil NJ, Marra MA, Ha T \& Baillie DL 1999 Identification and characterization of a serine hydroxymethyltransferase isoform in Caenorhabditis briggsae. Gene 230 137-144.

Wilson JD 1978 Sexual differentiation. Annual Review of Physiology 40 279-306.

Received in final form 20 August 2007

Accepted 29 August 2007

Made available online as an Accepted Preprint 30 August 2007 